\title{
BELO, Duarte. O núcleo da claridade: entre as palavras de Ruy Belo. Lisboa: Assírio \& Alvim, 2011.240 p.
}

\author{
Nuno Costa Santos \\ Cineasta / Roteirista / Escritor \\ Realizador do documentário Ruy Belo, era uma vez
}

omo é que um filho que é artista se pode aproximar
de um pai que também foi artista? Através da sua
própria arte - no caso, a fotografia. Duarte Belo, licenciado em arquitectura, é um reconhecido fotógrafo, com um percurso de exposições fotográficas individuais iniciado em 1989. Nascido em 1968, uma das marcas que já deixou é, além de um registo pessoal de diversas viagens a territórios muito distintos (Vila do Conde, Idanha, Açores, Amazónia etc.), uma significativa obra documental de levantamento fotográfico da paisagem portuguesa e da forma de ocupação do território, consagrada em livros como O sabor da terra (1997) e Portugal património (2007-2008). Através do seu trabalho e da sua investigação, também se tem aproximado do pai, um dos maiores poetas portugueses, Ruy Belo, num movimento sóbrio e meticuloso, próprio de quem sabe que não vai encontrar respostas óbvias, mas apenas pistas, fragmentos, janelas.

O primeiro gesto aconteceu em 2000 e tem o título Coisas de silêncio. O segundo, realizado dez anos mais tarde e também publicado pela Assírio \& Alvim, chama-se O núcleo da claridade. Em ambos os livros, Duarte Belo procura fixar aquilo que ficou do pai - os lugares, os objectos do quotidiano, as fotografias 
de rosto, as palavras. O primeiro conjunto de fotografias é acompanhado da escolha de uma série de poemas e de excertos de poemas, movimento que está de acordo com uma passagem de um texto de Ruy Belo, no ensaio "Poesia nova" (Revista Rumo, 1961): “[...] nunca a extensão do poema foi garantia de alta temperatura poética. Pelo contrário, dois ou três versos convenientemente isolados ferem-nos mais, muitas vezes, do que abundantes versos, em contínuo perigo de descambarem na prosa [...]". Os versos escolhidos em Coisas de silêncio, "mapa de visita" da paisagem humana do poeta, tocam os temas essencias da poesia do autor de Aquele grande rio Eufrates, de O problema da habitação-alguns aspectos e de Homem de palavra(s), dentre outros: Deus (ou melhor: deus) e a sua ausência, a morte, os amigos, o amor, o mar, a mulher, a infância, a alegria, a despedida. Tomem-se exemplos soltos, aqui sem origem bibliográfica: "[...] Os versos que faço sou-os [...]"; "[...] Somos a grande ilha do silêncio de deus [...]"; "Eu vinha para a vida e dão-me dias [...]". A última imagem do livro é, muito significativamente, a impressão digital do poeta-pai, a marca do dedo de quem esteve aqui para viver e sublimar a vida, nos seus diversos matizes, através da escrita.

Dez anos depois, na sua nova investida pelo rasto biográfico do pai, O núcleo da claridade - entre as palavras de Ruy Belo, o mapa é de outra ordem: feito de revisitas às fotografias do primeiro livro, do regresso aos lugares do poeta, como São João da Ribeira, Monte Abraão, Vila do Conde e Peniche, mas também - e sobretudo - de um "olhar" fotográfico sobre a poesia, sobre "os poemas autógrafos, os dactiloscritos, as provas de edições, a correspondência, os documentos dispersos, alguns objectos e as fotografias de época, que contextualizam uma vivência". Mais uma vez, sente-se o pudor da aproximação, tão assertiva como serena, com uma emoção que se pressente 
mas se esconde, num esforço de organização e de alinhamento característico do autor.

Podia dizer-se que Duarte assumiu corajosamente a tarefa de regressar ao pai sem necessitar da companhia de textos críticos e cúmplices. É ele e só ele que agora está diante do baú de uma ausência essencial. Citemos o próprio, na sua elegância discursiva:

Este não é um trabalho exaustivo sobre Ruy Belo, sobre a sua memória ou sobre o seu espólio literário. [...] É uma aproximação, com carácter fragmentário, para mim possível, a meu pai. Este é um livro sobre a vida e sobre o que permanece após a construção de um desígnio; um percurso sem um destino aparente, a vaga viagem da procura de um território nosso, unicamente humano.

Há o regresso a exactos lugares onde já havia estado para um trabalho anterior com o geógrafo Orlando Ribeiro, mas desta vez dá um enquadrado sentido à passagem do tempo. Afinal, O núcleo da claridade aparenta ser um esforço mais preciso, uma assumida forma de aproximação mais condensada, agora mapeada por legendas, rigorosamente orientadoras do leitor. Curiosamente, a dedicatória é mais pessoal, sendo endereçada aos irmãos, que tal como Duarte habitaram uma casa forrada de livros: "Este livro é para minha irmã Catarina e para o meu irmão Diogo, que comigo cresceram numa casa onde os livros ocultavam as paredes e a palavra era o valor absoluto da construção do ser e a face de cada um de nós".

Encontramos em $\mathrm{O}$ núcleo da claridade as casas (tema de um dos mais intensos poemas de Ruy Belo), a máquina de escrever, a máscara com que mergulhava no jardim marítimo, fac-símiles de poemas (escritos à mão ou dactilografados, como "Morte ao meio dia", "O Portugal futuro", "Vat 69", "Elogio de Maria Teresa", "Versos do pobre católico"), bilhetinhos, provas 
anotadas, traduções, capas de livros, exames da primária, livros de curso, facturas, contratos com editoras, declarações de rendimentos, cartas, jornais empilhados, relógios, portamoedas, bilhetes de identidade, fotografias de instantes decisivos.

Dos vários manuscritos e datiloscritos que se encontram no espólio de Ruy Belo, presentes em O núcleo da claridade, vejase o autógrafo do poema "Relatório e contas", de Boca bilingue:

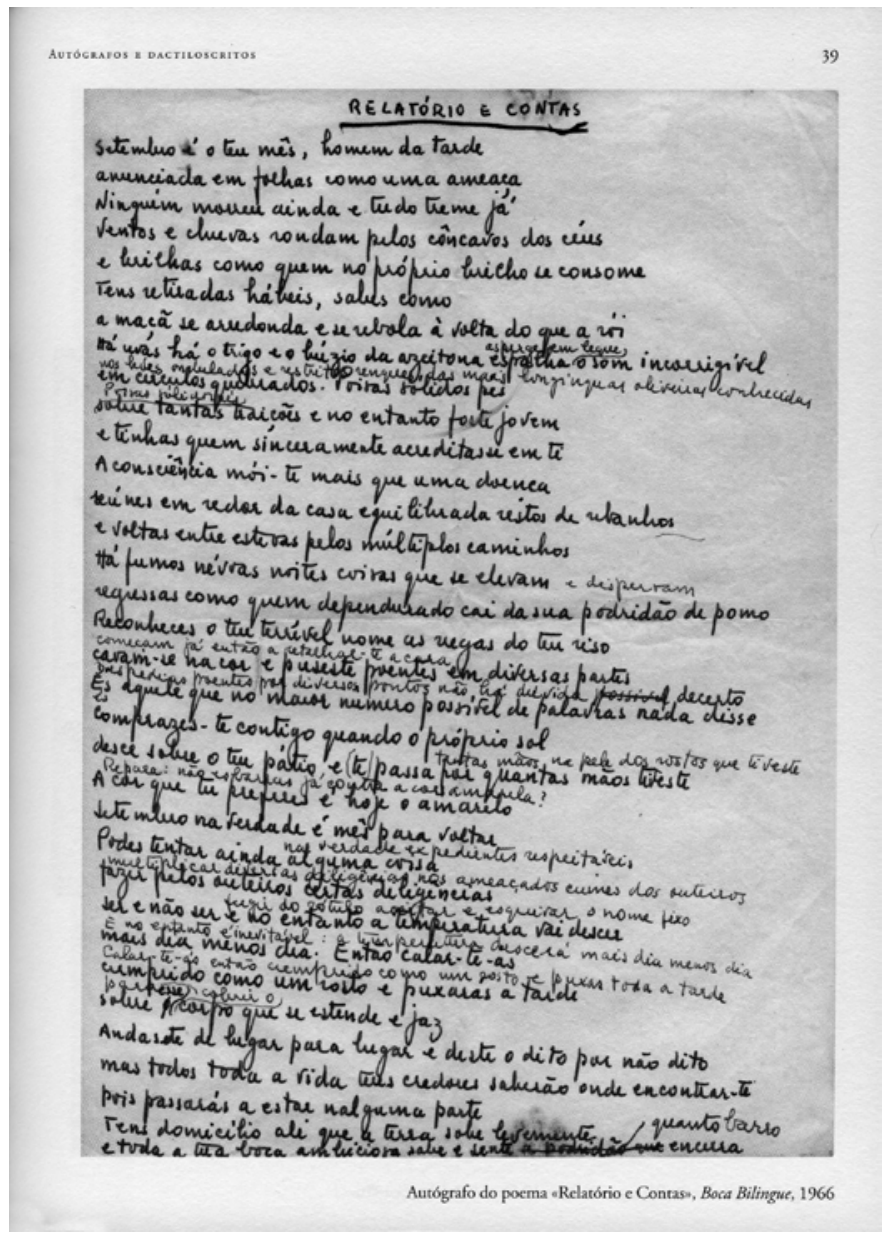


Destaque-se, também, o Bilhete de Identidade de cidadão português, que vemos na imagem:

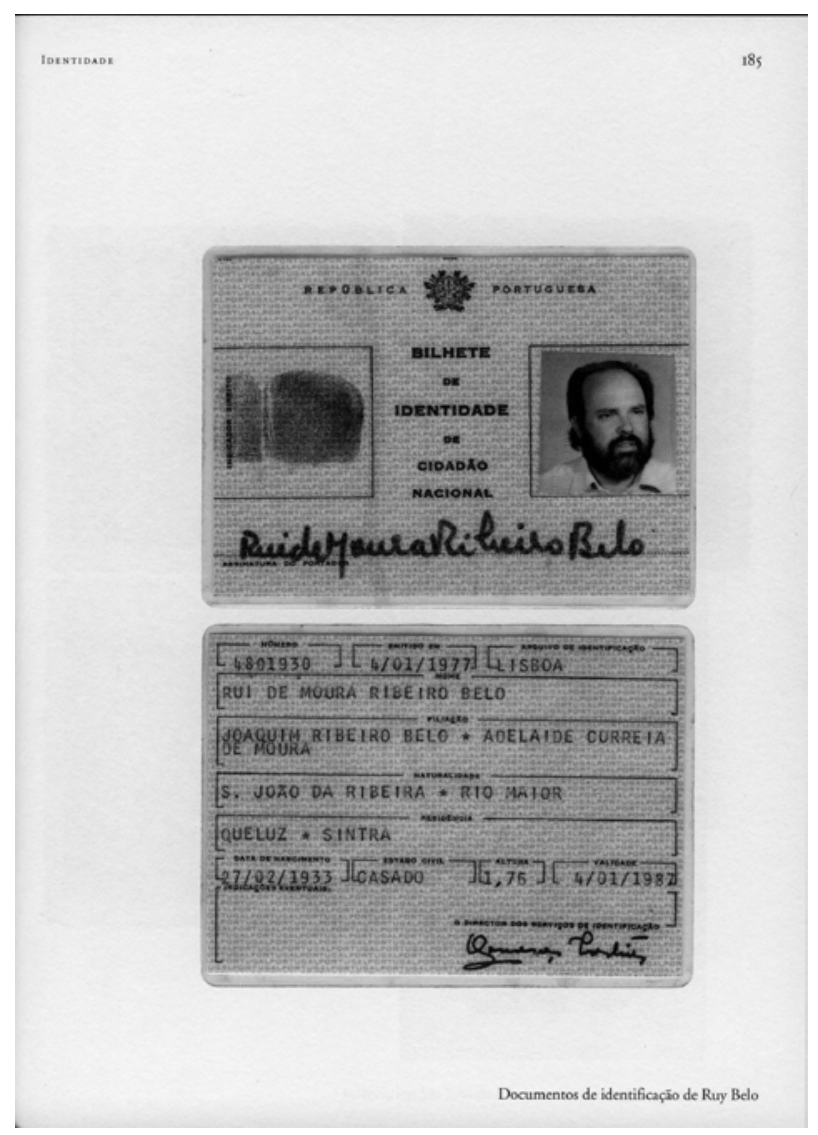

Tem-se, em O núcleo da claridade, um inventário significativo ou, se quiseremos, um álbum que cruza a palavra poética e o quotidiano, em si uma das marcas mais interessantes da obra de Ruy Belo, autor que assumia o dia a dia nos seus poemas e que tanto escrevia sobre o que tinha vivido como transfigurava a experiência num jogo literário para além da "verdade" da biografia. 